
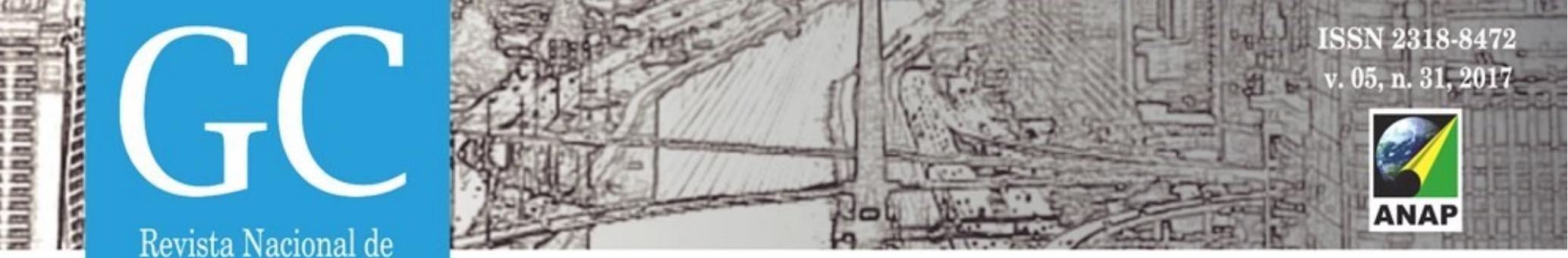

Gerenciamento de Cidades

National Journal of Cities Management

\title{
Gestão e diretrizes para conservação do patrimônio arquitetônico
}

Management and guidelines for conservation of the architectural patrimony.

Gestión y lineamientos para la conservación del patrimonio arquitectónico.

Claudio Silveira Amaral

Professor Doutor, UNESP-PPGARQ, Brasil.

cs.amaral@faac.unesp.br

Pamela Messias

Mestranda, UNESP-PPGARQ, Brasil. pamela.arquitetura@hotmail.com

Dionísio Vitorino Barbosa Junior

Mestrando, UNESP-PPGARQ, Brasil. diobarbosaarquiteto@gmail.com 


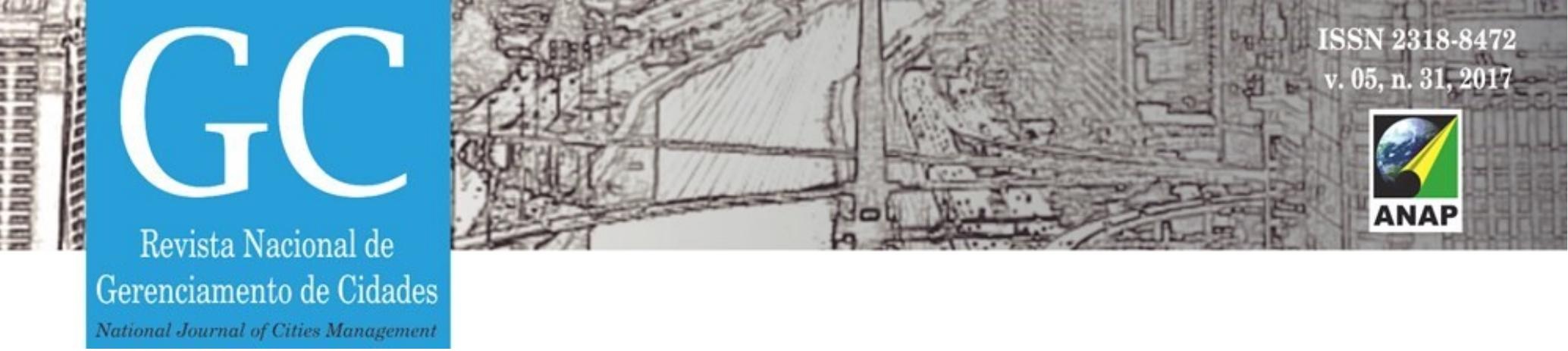

RESUMO

Ao mesmo tempo em que um patrimônio arquitetônico apresenta-nos carregado de sua experiência formal, ele também nos apresenta seu contexto contemporâneo, partindo para infinitas possibilidades de interação Monumento-Entorno-Sociedade. Muitas vezes esses entornos, associados a outros fatores como o tempo, desastres naturais e ações públicas e sociais de abandono, causam a degradação e a morte prematura desses patrimônios. Este trabalho tem como objetivo delinear as teorias de conservação em patrimônios arquitetônicos de John Ruskin, considerando para isso os processos e as práticas que podem ser aplicadas de forma que o monumento e seu entorno não percam o valor cultural decorrente de sua degradação e abandono. Levamos em consideração as teorias sobre patrimônio arquitetônico de John Ruskin e as principais correntes de pensamento no Brasil e no mundo. A conservação deve ser entendida como um processo sistemático, preventivo ou corretivo, sendo a melhor maneira de se preservar qualquer patrimônio histórico, tombado ou não. Deve ser também entendido imprescindivelmente com uma função social, que pode ou não se modificar ao logo do tempo. A discussão da conservação de edifícios de patrimônio arquitetônico, sua relação social, temporal e material contribui para apontar as formas mais relevantes de se fazer processos de conservação.

PALAVRAS-CHAVE: Patrimônio Arquitetônico. Conservação. Gestão Pública.

\section{ABSTRACT}

At the same time that an architectural patrimony presents us loaded with its formal experience, it also presents us its contemporary context, leaving to infinite possibilities of interaction Monument-Environment-Society. Often these environments, associated with other factors such as weather, natural disasters and abandonment public and social actions, cause degradation and premature death of these assets. This work aims to outline the theories of conservation in architectural heritage of John Ruskin, considering for this the processes and practices that can be applied so that the monument and its surroundings do not lose the cultural value due to its degradation and abandonment. We take into account John Ruskin's theories of architectural patrimony and the main currents of thought in Brazil and in the world. With the design of conservation theories, this process must become systematic, preventive or corrective, and Conservation is the best way to preserve any patrimony, whether or not it is registered. It must also be understood as having a social function, which may or may not change over time. The discussion of the conservation of architectural heritage buildings, their social, temporal and material relationship contributes to point out the most relevant forms of conservation processes.

KEY WORDS: Architectural Heritage. Conservation. Public administration.

\section{RESUM}

Al mismo tiempo, un patrimonio arquitectónico da nos llena de experiencia formal, sino que también nos presenta con su contexto contemporáneo, a partir de un sinfín de posibilidades de interacción monumento-AlrededoresSociedad. A menudo estos entornos, asociados con otros factores tales como el clima, los desastres naturales y pública y acciones sociales de abandono, causan la degradación y la muerte prematura de estos activos. Este documento tiene por objeto describir la conservación del patrimonio arquitectónico en las teorías de John Ruskin, teniendo en cuenta esto a los procesos y prácticas que pueden ser aplicadas de manera que el monumento y su entorno no se pierda el valor cultural debido a su degradación y abandono. Tenemos en cuenta las teorías de la herencia arquitectónica de John Ruskin y las principales corrientes de pensamiento en Brasil y en todo el mundo. Con el diseño de la teoría de la conservación, este proceso debería ser sistemática, preventivo o correctivo, con la conservación de la mejor manera de preservar los activos, la lista o no. También debe entenderse indispensablemente con una función social, que pueden o no cambiar el momento adecuado. La discusión de la conservación de los edificios arquitectónicos del patrimonio, las relaciones sociales, el tiempo y los materiales de ayuda para precisar las formas más pertinentes para que los procesos de conservación.

PALABRAS CLAVE: Conservación. Patrimonio arquitectónico. Gestión pública. 


\section{OBJETIVO}

O presente trabalho tem por objetivo propor políticas públicas para a conservação do patrimônio arquitetônico na gestão pública brasileira, com base na fundamentação teórica de Ruskin e a função social do edifício histórico.

\section{MÉTODOLOGIA}

O estudo compreende quatro etapas: Primeira, a definição do valor do patrimônio, seguindo para a conservação do patrimônio e o Delineamento do pensamento ruskiniano. Segunda, as teorias de conservação de Ruskin e a leitura e interpretação de seus sucessores.

Terceira, para a conservação do patrimônio levam-se em conta as principais correntes de pensamento no Brasil e no mundo, é esse valor que condiciona as práticas adotadas em torno da sua conservação.

Quarta, com o delineamento das teorias de conservação propor-se-á as políticas públicas para a conservação do patrimônio arquitetônico na gestão pública brasileira.

\section{RESULTADOS}

A palavra Patrimônio está historicamente relacionada á noção de sagrado, de herança. A ideia de um patrimônio comum a um grupo social, definidor de sua identidade e enquanto, tal merecedor de proteção, nasce com a visão moderna de história e de cidade (BABELON e CHASTEL,1994 apud SANTOS, 2001, p. 43). Se um patrimônio é preservado, é preciso estabelecer limites físicos e conceituais, regras e leis para que isso aconteça: "Foi a ideia de nação que veio garantir o estatuto ideológico (do patrimônio) e foi o Estado nacional que veio assegurar, através de práticas específicas, a sua preservação (...)" (FONSECA, 1997, p.54-59 apud SANTOS, 2001, p. 43).

A constituição de 1988 traz a afirmação no seu artigo 30: “Compete aos Municípios promover a proteção do patrimônio histórico-cultural local, observar a legislação e a ação fiscalizadora federal e estadual". Essa afirmação tem um caráter de abertura conceitual do patrimônio ao município, mas sem tirar a responsabilidade da União sobre o mesmo (ARANTES, 1996, p. 11). De acordo com o primeiro documento criado para nortear as ações de proteção do Patrimônio cultural, "Carta de Atenas" de Outubro de 1931, a salvaguarda é definida por uma série de fatores que envolvem cada caso especificamente, mas podemos diagnosticar normas de conduta para manter o bem cultural (IPHAN, 1995, p 13-21). A primeira delas é manter o bem cultural, e dentro dele extrairemos o bem arquitetônico, em uso constante e satisfazendo os programas originais.

Em 1964 surge a Carta de Veneza, que define como monumento histórico: 
"Toda criação arquitetônica isolada, bem como o sítio urbano ou rural que dá testemunho de uma civilização particular, de uma evolução significativa ou de conhecimento histórico. Incluíram-se as obras modestas com significado cultural" (IPHAN, 1995, p 107-113).

Essa mesma carta traz a recomendação da valorização dos monumentos, através do respeito à vizinhança dos monumentos antigos, cuja proximidade deve ser objeto de cuidados especiais, a preservação de algumas perspectivas pitorescas em certos conjuntos e a supressão de toda publicidade, presença abusiva de postes, fios e de toda a indústria ruidosa na vizinhança ou na proximidade dos monumentos de arte ou de história (IPHAN, 1995, p 13-21).

O caráter meramente simbólico do patrimônio está sendo deixado de lado para ser estudado, discutido, compartilhado e até mesmo reivindicado. Ultrapassando o caráter de Monumento para abranger o vernacular, o cotidiano, a imaterialidade sem abrir mão de contemplar a preservação dos objetos de arte e monumentos eleitos ao longo de tantos anos de trabalho merecedor de proteção especial (SANTOS, 2001, p. 44).

A noção de Patrimônio se constitui em uma rede simbólica do próprio homem, relacionado ao conhecimento acumulado e à memória. O conceito de Patrimônio pode carregar dezenas de significados, tais como a noção de paternidade, herança, legado e posse que vêm da sua origem latina (FONSECA, 2008).

Sob a égide de Choay (2006, p.157-160), na França, um monumento histórico não é visto como uma relíquia que se destina à efetiva memória. Ele é um objeto historicamente determinado e suscetível a uma analise racional. A abordagem francesa é impensável para Ruskin, restauração é o oposto da conservação. Para Viollet-le-Duc "Restaurar um edifício é restitui-lo a um estado completo que pode nunca ter existido num monumento", aborda uma concepção "ideal" do monumento histórico, explica que essa intervenção drástica e "agressiva" é para manter vivo os monumentos antigos que se encontram "mortos", como se fossem testemunhas de sistemas históricos obsoletos e que tem como principal interesse sinalizar o espaço vazio. Na Itália e em outros lugares, os princípios de Viollet-le-Duc inspiraram a maioria das grandes restaurações, onde Ruskin e seu seguidor Morris os atacavam diretamente. Confrontando com essas duas doutrinas antagônicas, Boito recolhe o melhor de cada uma, e é levado a formular um conjunto de diretrizes para a conservação e restauração dos monumentos históricos, incorporadas à lei italiana de 1909 (CHOAY, 2006).

A Carta de Veneza de 1964 (apud IPHAN, 1995, p. 110-111), expressa que a restauração: "é uma operação que deve ter caráter excepcional, que tem por objetivo consertar e revelar os valores estéticos e históricos do monumento e fundamentar-se no respeito ao material original e aos documentos autênticos. A Restauração será sempre precedida e acompanhada de um estudo arqueológico e histórico do monumento".

A Conservação é definida como a manutenção permanente pela Carta de Veneza (1964). Também implica em seu uso permanente e útil a sociedade, mantendo assim seu uso social. Não admite alterações de volumes e cores, deslocamentos ou ausência de elementos. Na 


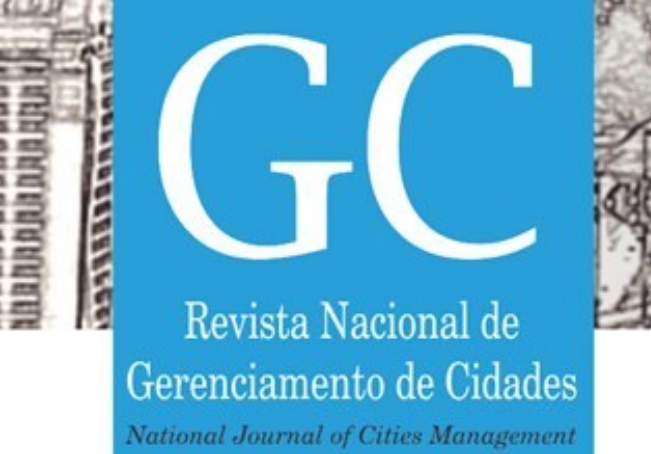

No Brasil, as teorias de Ruskin se enquadram apenas no campo do patrimônio, como uma das principais referências de teoria de conservação, prática projetual e de ambientação. Não estamos acostumados a entende a discussão da divisão do trabalho como sendo o tema principal abordado por Ruskin. O motivo principal desse distanciamento é que as teorias de Ruskin chegam ao Brasil junto com o projeto dos modernos, junto com os primeiros diagnósticos de nosso "atraso" e das mudanças nas relações de trabalho e progresso da técnica estavam sendo implantados (LIRA, 2006).

Para entender a complexidade do pensamento de John Ruskin é preciso saber que suas preocupações se enquadram no homem. Em uma era de mudanças como se passou no século $\mathrm{XIX}$, o trabalho do homem é o centro das discussões e dos pensamentos. Para o homem poder fazer seu trabalho, e através dele encontrar a felicidade e seu caráter enobrecedor do homem, Ruskin cria uma teoria muito particular sobre a forma como "vê" o mundo.

A lógica espacial de Ruskin (apud Amaral, 2008) é dividida em três fases: a) A Natureza; b) A Pintura; c) A Arquitetura. Essas fases se desdobram em temas que se misturam ao longo de seus discursos. Esses temas podem ser divididos em: a forma natural, a primeira impressão, a tecnologia, a composição natural, a estética natural, a composição na pintura, a composição na arquitetura. O método ruskiniano entrelaça tudo o que existe procurando dar uma noção de ordem, equilíbrio e lógica.

No tema "natureza", Ruskin toma o olhar como papel fundamental, e para ele tudo o que existe na natureza possui uma parte material (desenho) e outra espiritual (moral). A aplicação da composição natural é o relacionamento entre os elementos naturais com uma ética. Ruskin também cria uma teoria da percepção baseada na apreensão de um espírito no ato de visualização do objeto através do primeiro contato visual. Essa primeira impressão é capaz de fazer associações à diversas forças metafísicas sem origem conhecida, isto é, em vários assuntos que brotam da memória do espectador. Chamou essa percepção de sublime, pois é imprecisa, grandiosa e acima da compreensão humana, o sublime salta fora do objeto. As "verdades ruskinianas" surgem de um estado de contemplação: apreensão das sensações transmitidas por um objeto a um espectador. A verdade só pode ser entendida a partir de uma primeira impressão ou primeiro contato visual (AMARAL, 2008).

Na composição natural, o que interessa para Ruskin é o resultado dessa relação, que tem que ser harmoniosa, em relação de ajuda mutua ou de troca justa, pois em uma relação de competição não se alcança o equilíbrio. Implica ai uma ética religiosa. E para a composição ser bela a composição tem que ser criativa e inédita, como na natureza. Nenhum elemento isolado é considerado belo ou não-belo (AMARAL, 2008).

Ruskin elegeu a arquitetura como a maior das artes, pois ela abrange uma escala de intervenção maior que as outras artes. A categoria arquitetônica para Ruskin é o espaço do dia-a-dia, é toda a cidade e o espaço urbano. As leis da arquitetura ruskinianam, através de "Sete lâmpadas da Arquitetura", são elaboradas através de metáforas, é preciso entender o que realmente Ruskin que dizer nessas leis. A primeira lei e a do "Sacrifício", é uma exigência, 


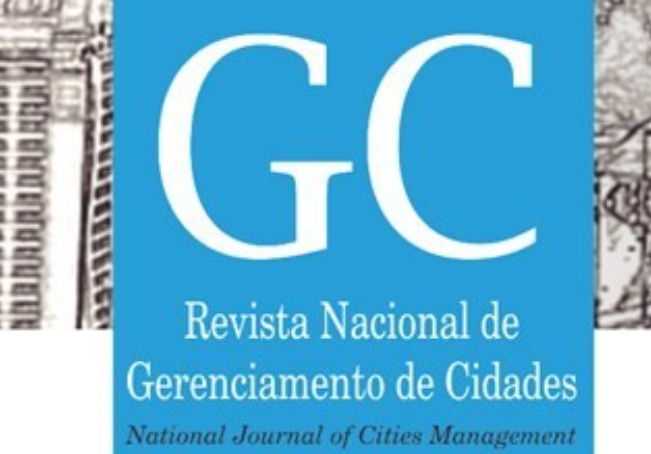

pois para ser um artista ou arquiteto, ou até mesmo antes de desempenhar qualquer profissão é necessário seu sacerdócio. O que Ruskin quer dizer é que é preciso aderir a uma ideologia, tem um comprometimento ideológico. As outras leis são as "verdades das estruturas" e "verdades dos materiais". "As verdades da Arquitetura" de Ruskin (apud AMARAL, 2008) derivam da sua lógica da composição natural. O equilíbrio só ocorre depois dos elementos estruturados terem sido desenhados e de acordo com a resistência estruturais dos materiais e as intensões programadas. E é por esse motivo que as estruturas devem ser expostas, para mostrar os esforços ao observador, agregando a sensação de segurança e de sublimidade.

Já a noção de estética arquitetônica deriva da noção de ornamento de Ruskin (apud AMARAL, 2008), atribuiu ao ornamento e à estética a função de registrar a história e as características locais, além de imprimir o gosto pessoal do trabalhador que executa a obra. A estética de fazer o certo é entendida como uma estética que imita um já realizado, era uma cópia e o fazer errado era espontâneo, algo novo e criativo.

A verdade dos materiais também deriva da forma da natureza: os materiais usados devem expressar sua verdade, o caráter do material diz que ele possui seu processo de envelhecimento próprio e esse envelhecimento traz dignidade ao material, pois acrescenta os sinais do tempo. Toda requalificação espacial da arquitetura é entendido como uma falsificação da história, por isso a substituição de materiais não é admitido por Ruskin, mas ele não é contra o restauro, é contra a adulteração do desenho original e da falsificação dos materiais (AMARAL, 2008).

Ruskin e Conde Zorzi saíram em defesa do restauro da Catedral de São Marcos, em 1870, por desejava um restauro que não alterasse as características originais da obra, queria que os materiais empregados fossem trocados por similares envelhecidos para não destoarem dos que permaneciam. Conde Zorzi publicou um livro com os princípios da teoria de percepção de Ruskin, o que salvou a Catedral da intervenção que estava em curso e previa a substituição e o redesenho das partes da igreja (AMARAL, 2008).

O principal assunto tratado por John Ruskin é uma teoria de lógica e de razão, e estrutura temas de várias áreas distintas como Arquitetura, Pintura, Política, Religião e outras. Ruskin possuía um pensamento espacial e visual e sua lógica visual era oposta a lógica formal adotada na época (AMARAL, 2011). Pois ao invés de fazer uma argumentação de sai de um ponto para chegar a outro ponto, linearmente, ele irá superpor assuntos de seu tempo para compor sua argumentação. Também trabalha em uma razão baseada na observação da natureza, chamado de logica da natureza: as partes compõem para dar sentido a um todo, e esse todo é composto por objetos, efeitos, sensações, memórias, cores, etc. Fazendo uma leitura de Ruskin visualizando o todo, e não as partes que compõem sua argumentação, passa-se assim a entender o seu método e resultando em uma interpretação onde os temas são menos importantes que o método.

Ruskin se comporta como um profeta emitindo as suas Verdades. Mas não utilizou regras para ensino do desenho, pois acreditava que cada aluno deveria criar seu próprio método empírico 


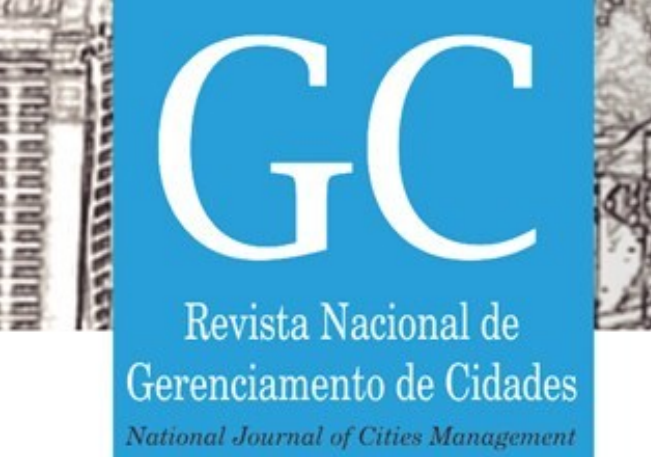

Edifício tenha atingido sua Sublimidade antes de quatro ou cinco séculos. (Ruskin, 2008, p.7778).

\section{CONCLUSÃO}

O mais importante é entender que a arquitetura tem que ser construída e entendida como um legado histórico, e que não temos o direito ou permissão para mudar ou transformar esse legado.

Dentre as principais recomendações, há a importância das residências no patrimônio de uma cidade, por isso elas devem ser duráveis e perfeitas. Na verdade diz que toda construção deve ser pensada para uma longa duração, com materiais duráveis e autênticos como: madeira, pedras, cerâmicas, concreto, aço, tijolos, etc.

A conservação é crucial para que não se precise restaurar, ela deve ser um processo permanente e sistemático. A conservação, em comparação aos outros tipos de intervenção, é a mais econômica, pois usa menos recursos materiais e de serviços especializados, que acrescenta elementos não originais ou prejudiciais ao seu entendimento como patrimônioherança e reduz muito o deslocamento dos usuários ou mudança de propriedade. E em comparação ao abandono evita o depreciamento e desgaste, pois com a manutenção de seu uso adequado ele sofre menos com o desgaste, pois recebe limpeza constante, pequenos reparos como pintura, aplicação de impermeabilizantes, troca de telhas, etc.

É primordial que não se alterem os materiais e os espaços, tentar mostrar essas características como se fossem novas é uma grave forma de depreciação do patrimônio. Na verdade as impressões do tempo no patrimônio é o que importa, é nela que a história é contada, foi vivida e ao menos pode ser "vista".

A conservação implica na manutenção da memória coletiva, pois entendemos que o patrimônio não é algo estático em um tempo passado e sim como herança viva, e que deve ser parte integrante da sociedade contemporânea.

É nosso papel discernir na comunidade civil e acadêmica que o tombamento não é uma punição, não é um enrijecimento do bem, e sim que deve ser inserido na sociedade contemporânea, através principalmente de seu uso. E para que essa ideia seja compreendida há a possibilidade de instrumentos dos estados federais, estaduais e municipais em contrapartida. Como por exemplo, na esfera federal, a criação de linhas de créditos (financiamentos) para intervenções de conservação. E na esfera municipal a isenção de IPTU (Imposto Predial Territorial Urbano) e emolumentos a seus proprietários.

\section{REFERÊNCIAS BIBLIOGRÁFICAS}

AMARAL, C. S. A lógica espacial de John Ruskin. Oculum Ensaios, 7, 2008. 
